\title{
Atypical form of atrioventricular septal defect without left axis deviation: relation between morphology and unusual QRS axis
}

Departments of Paediatric Cardiology and Cardiac Surgery, Sakakibara Heart Institute, Tokyo, Japan K Suzuki Y Murakami K Tatsuno Y Takahashi T Kikuchi K Mori $S$ Mimori

Correspondence and requests for reprints to: Dr K Suzuki, Department of Paediatric Cardiology, Sakakibara Heart Institute, 5-4 Yoyogi 2-chome Shibuya-ku Tokyo 151, Japan.

Accepted for publication 4 January 1993

Kiyoshi Suzuki, Yasuo Murakami, Katsuhiko Tatsuno, Yukihiro Takahashi, Toshio Kikuchi, Katsuhiko Mori, Shigekazu Mimori

\begin{abstract}
Objective-To clarify the morphological features relating to an intermediate axis or a right axis deviation in atrioventricular septal defect (AVSD).

Subjects-135 patients with typical AVSD and with nine patients with atypical AVSD, characterised by a well formed atrial septum, a milder downward displacement of the atrioventricular valves, and a shorter length of the ostium primum defect.
\end{abstract}

Main outcome measures-Relation between morphology and electrocardiographic and vectorcardiographic findings; prevalence of Down's syndrome and of other cardiac anomalies.

Results-All nine patients with atypical AVSD had an unusual mean frontal QRS axis compared with six of the 135 patients (4\%) with typical AVSD (p < $0 \cdot 01)$. All eight patients who underwent the vector analyses showed atypical movement of the QRS loop-that is, an initial left inferior movement in the frontal loop (eight patients) and counterclockwise rotation in the sagittal loop (seven). The corresponding values for 119 patients with typical AVSD were 20 and 22 patients $(p<0.01)$. Seven patients with atypical AVSD (78\%) and 55 (41\%) with typical AVSD had Down's syndrome $(p<0.05)$. None of the twenty one patients with additional cardiac anomalies had atypical AVSD, an unusual QRS axis, or unusual movement in the QRS loop.

Conclusions-The atypical morphology, supposedly related to the degree of posteroinferior displacement of the conduction system, was one of the causes of unusual movement of the QRS loop in AVSD.

(Br Heart f 1993;70:180-184)

The anatomical features of atrioventricular septal defect (AVSD) are a common atrioventricular junction guarded by a five leaflet valve, an unwedged position of the subaortic outflow tract, and an inlet/outlet disproportion of the ventricular mass. ${ }^{12}$ Left axis deviation in the mean frontal QRS plane is believed to be associated with posteroinferior displacement of the atrioventricular conduction system as a result of these anatomical features. ${ }^{3-5}$ We have, however, encountered patients with atypical morphology (atypical AVSD), whose features are a well formed atrial septum, a milder downward displacement of the atrioventricular valves, and a shorter length of the ostium primum defect (figs 1 and 2).

In this study we clarified the clinical findings of atypical AVSD, including its electrocardiographic patterns.

\section{Patients and methods}

A total of 144 patients with atrioventricular septal defect with usual arrangement were studied at this institute between December 1977 and September 1992. In 66 cases the patients were male and 78 female. Ages ranged from newborn to 72 years, four patients being more than 60 years old. Patients with a heterotaxic heart were excluded from this study. In the patients who did not undergo the intracardiac repair the diagnosis was based on echocardiographic and angiographic findings. Fifty three patients had an ostium primum defect with a three leaflet left atrioventricular valve (incomplete form), and 76 patients had superior and inferior bridging leaflets with both interventricular and interatrial communications (complete form). The remaining 15 patients had a bridging leaflet but no interventricular communication. Fourteen patients also had pulmonary stenosis, five coarctation of the aorta, and two a hypoplastic left ventricle. Sixty two patients had Down's syndrome.

Nine patients had morphological features consistent with atypical AVSD, the remaining 135 showing features of the typical form. To clarify the differences between these two types we compared (a) morphological features and haemodynamic stress, (b) relation to Down's syndrome, $(c)$ electrocardiographic and vectorcardiographic findings, and (d) postoperative course.

Results

MORPHOLOGICAL FEATURES AND

HAEMODYNAMIC STRESS

Of the nine patients with atypical AVSD, five had the complete type and four the incomplete type (table). We found three detailed morphological features of atypical AVSD.

(1) In an echocardiogram, a well formed atrial septum seemed to connect normally with the atrioventricular valves during the systolic phase (figs 3 and 4). In typical AVSD, the defect was large enough to be 


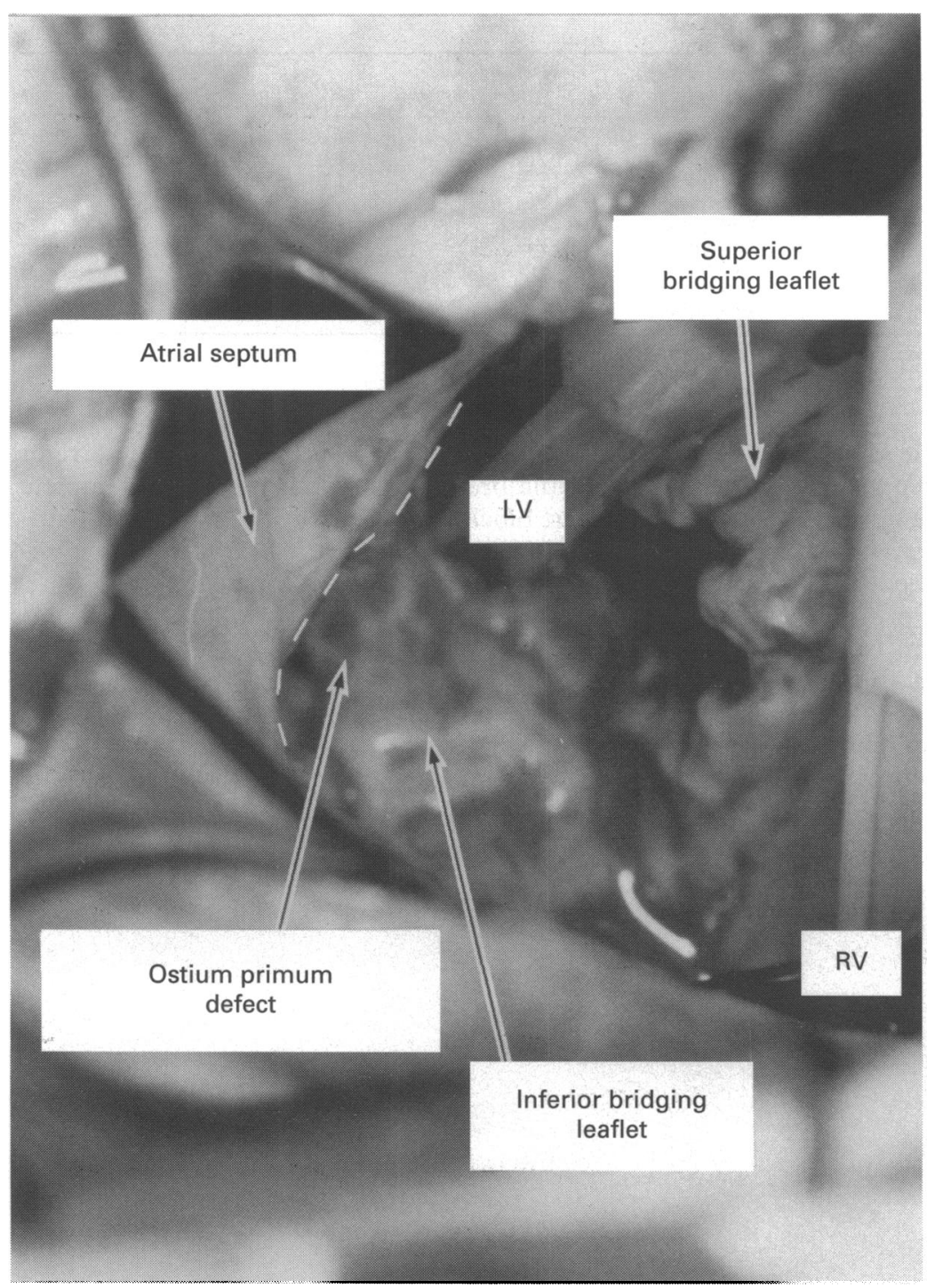

Figure 1 Atypical atrioventricular septal defect (case 4). The atrial septum is well formed and the ostium primum defect too small to observe the left side of the common atrioventricular orifice. ( $L V$, left ventricle; $R V$, right ventricle)

always delineated. At operation the ostium primum defect in atypical AVSD was too small to observe the mitral component (figs 1 and 2).

(2) Deficiency of the ventricular inlet septum, which was measured by echocardio- graphy, was milder than that in typical AVSD (figs 3 and 4).

(3) The length of the ostium primum defect was shorter than that in typical AVSD (fig 2).

In patients with the incomplete form of atypical AVSD right ventricular pressure was almost normal (table). None of the twenty one patients with associated cardiac abnormalities had any features of atypical AVSD.

\section{RELATION TO DOWN'S SYNDROME}

Seven out of nine $(78 \%)$ patients with atypical AVSD had Down's syndrome (table) compared with 55 out of 135 (41\%) patients with typical AVSD ( $p<0.05)$.

ELECTROCARDIOGRAPHIC AND VECTORCARDIOGRAPHIC FINDINGS

All nine patients with atypical AVSD had a mean frontal QRS axis ranging from 0 to +179 in an electrocardiogram (figs 5,6 and 7 ). In contrast, only six patients (4\%) with typical AVSD had an unusual QRS axis $(p<0.01)$. Figure 7 shows the QRS patterns in patients with atypical AVSD in a Frank vectorcardiogram. The eight patients had an initial left inferior movement in the frontal loop, of which five (63\%) showed a clockwise rotation. The left sagittal loop moved counterclockwise in seven patients $(88 \%)$. Of 119 patients with typical AVSD, however, 20 $(17 \%)$ had an initial left inferior movement in the frontal loop, of which eight $(7 \%)$ showed a clockwise rotation. The left sagittal loop moved counterclockwise in 22 patients $(18 \%)$. These differences were significantly different between the two groups $(p<0.01)$. Movement of the horizontal loop reflected the degree of right ventricular hypertrophy and showed the same patterns in the two types of AVSD. None of the twenty one patients with associated cardiac abnormalities showed either the unusual mean frontal QRS axis or the atypical QRS movement in a vectorcardiogram.

\section{POSTOPERATIVE COURSE}

Seven patients with atypical AVSD (five with the complete form and two with the incom-
Figure 2 Typical and atypical AVSD (complete form). In atypical $A V S D$ a well formed atrial septum obscures the left side of the common atrioventricular orifice. The length of the ostium primum defect (a to b) is shorter than that in typical $A V S D$. ( $L V$, left ventricle; $R V$, right ventricle).
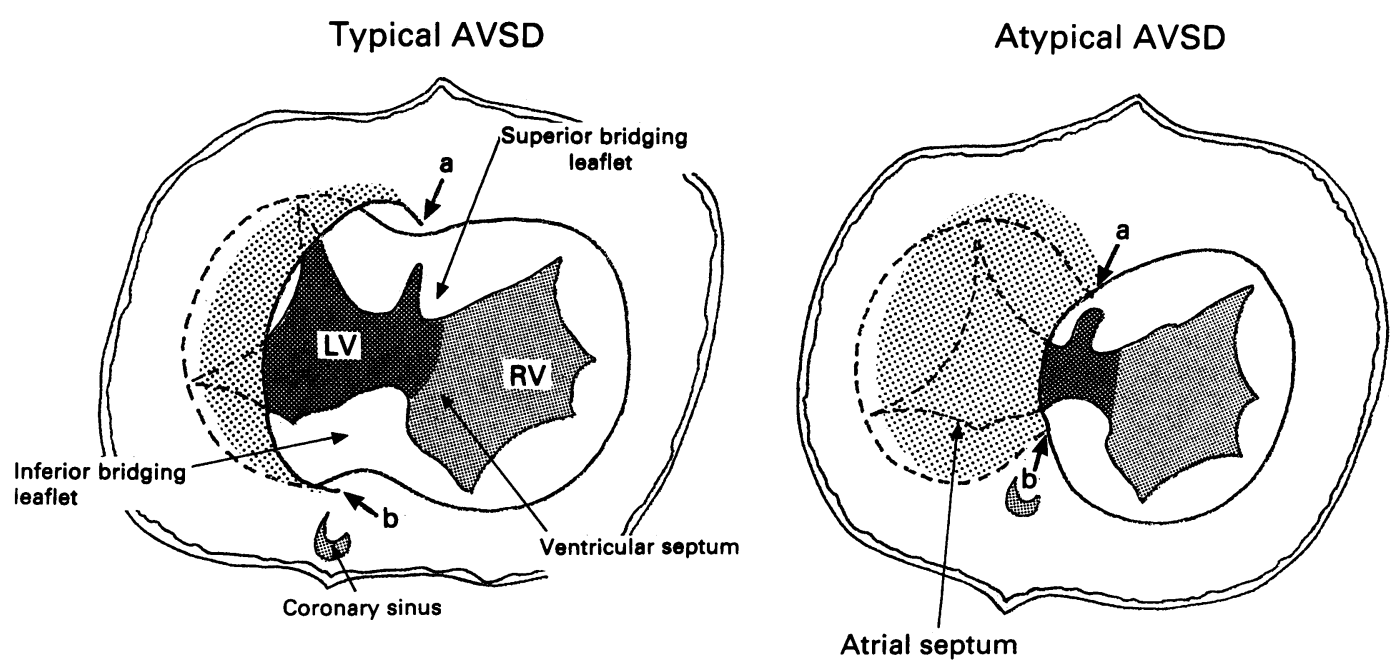
Clinical details of patients with atypical AVSD

\begin{tabular}{lllllll}
\hline $\begin{array}{l}\text { Case } \\
\text { No }\end{array}$ & Age & Sex & Type of defect & $\begin{array}{l}\text { Down's } \\
\text { syndrome present }\end{array}$ & $R V p / L V p$ & $\begin{array}{l}\text { Severe mitral } \\
\text { regurgitation present }\end{array}$ \\
\hline 1 & 3 months & F & Complete & Yes & 1.0 & No \\
2 & 8 months & F & Complete & Yes & 1.0 & No \\
3 & 9 months & Y & Complete & Yes & 1.0 & No \\
4 & 1 year & Complete & Yes & 1.0 & No \\
5 & 13 years & M & Complete & Yes & 0.4 & Yes \\
6 & 4 years & Incomplete & Incomplete & Yes & 0.3 & Yes \\
7 & 7 years & F & Incomplete & No & 0.3 & No \\
8 & 27 years & F & Incomplete & No & 0.4 & No \\
9 & 72 years & & & & \\
\hline
\end{tabular}

$\mathrm{RVp} / \mathrm{LVp}=$ pressure ratio between right ventricle and left ventricle.

plete form) underwent the same operation for intracardiac repair as the patients with typical AVSD. In the complete form a ventricular patch was sutured underneath the bridging leaflets without cutting the leaflets or chordae tendineae. The ostium primum defect was closed with another patch. In four cases (two with the complete form and two with the incomplete form) the coronary sinus was placed in the right atrium and in the remaining three cases in the left atrium. After the operation four patients had a complete right bundle branch block, but none had complete heart block. The incidence of the risk of damage to the conduction system was not significantly different between the two types.

\section{Discussion}

The electrocardiographic findings of AVSD are a left axis deviation in the frontal plane, with most axes directing northwest in the
Figure 3

Echocardiographic findings in incomplete form of atypical AVSD (case 9). (A) Apical four chamber view in the systolic phase. The atrial septum seems to connect normally with both of the atrioventricular valves. Downward displacement of the atrioventricular valves is mild. (B) In the diastolic phase a defect is delineated in the lower part of the atrial septum. ( $L A$, left atrium, $L V$, left ventricle, $R A$, right atrium, $R V$, right ventricle.)

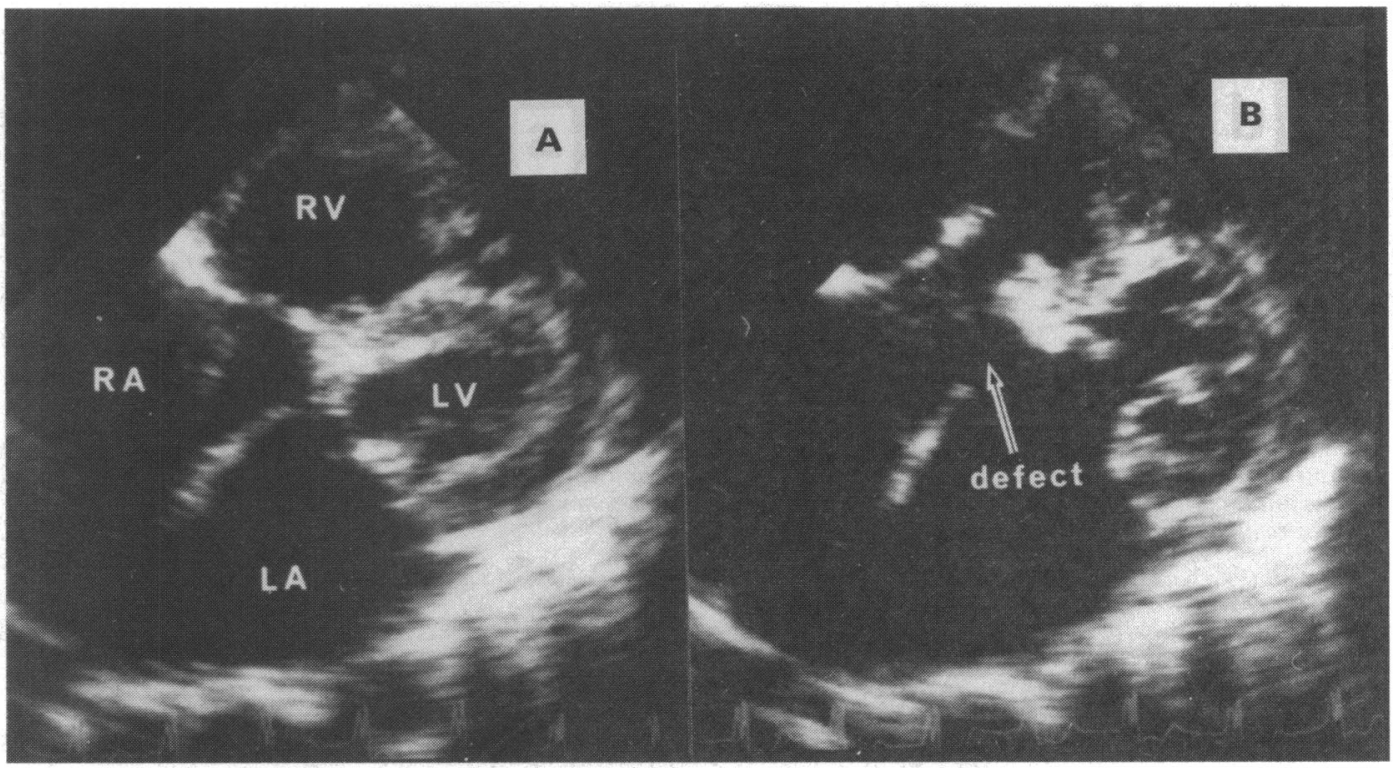

Figure 4

Echocardiographic findings in complete form of atypical $A V S D$ (case 4). (A) Apical four chamber view in the systolic phase. The atrial septum seems to connect normally with the atrioventricular valves, which are positioned normally. (B) In the diastolic phase a large defect is delineated in the lower atrial septum and the inlet of the ventricular septum. ( $L A$, left atrium, $L V$, left ventricle, $R A$, right atrium, $R V$, right ventricle, $V S D$, ventricular septal defect.)

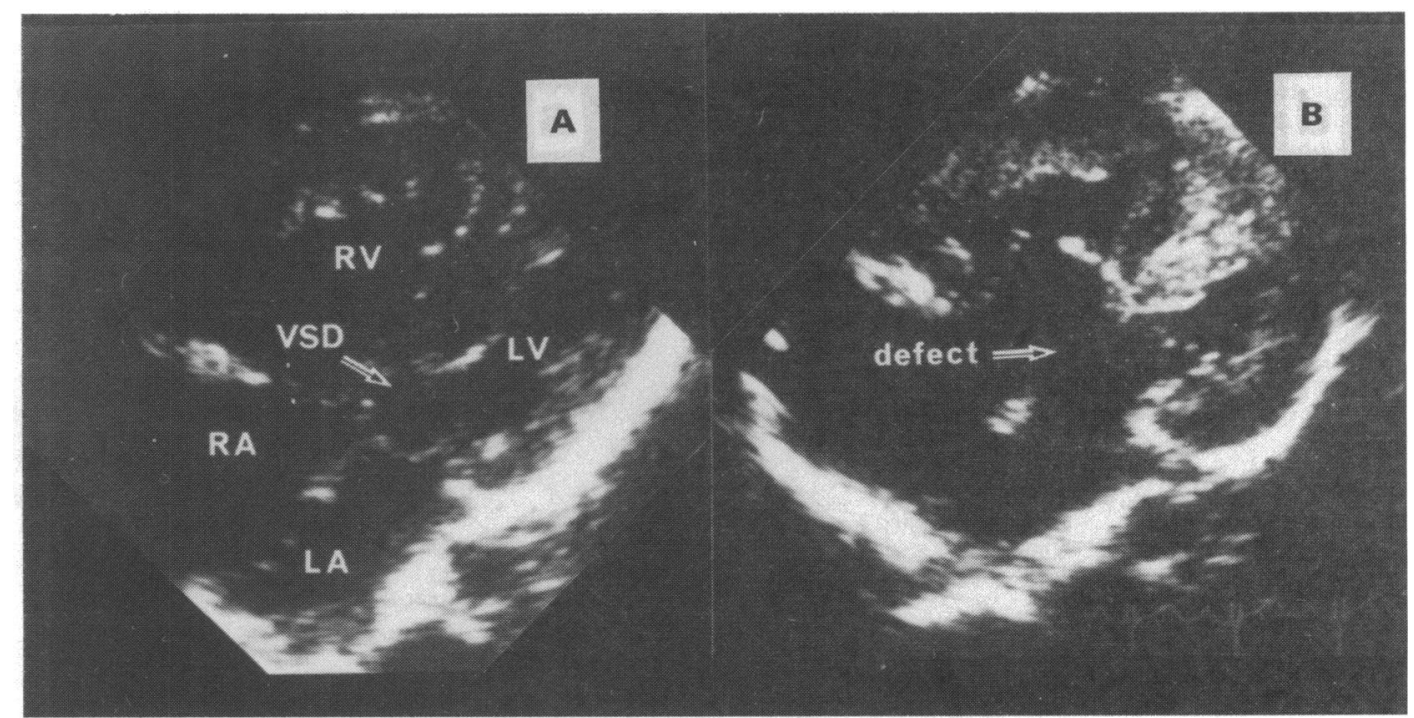




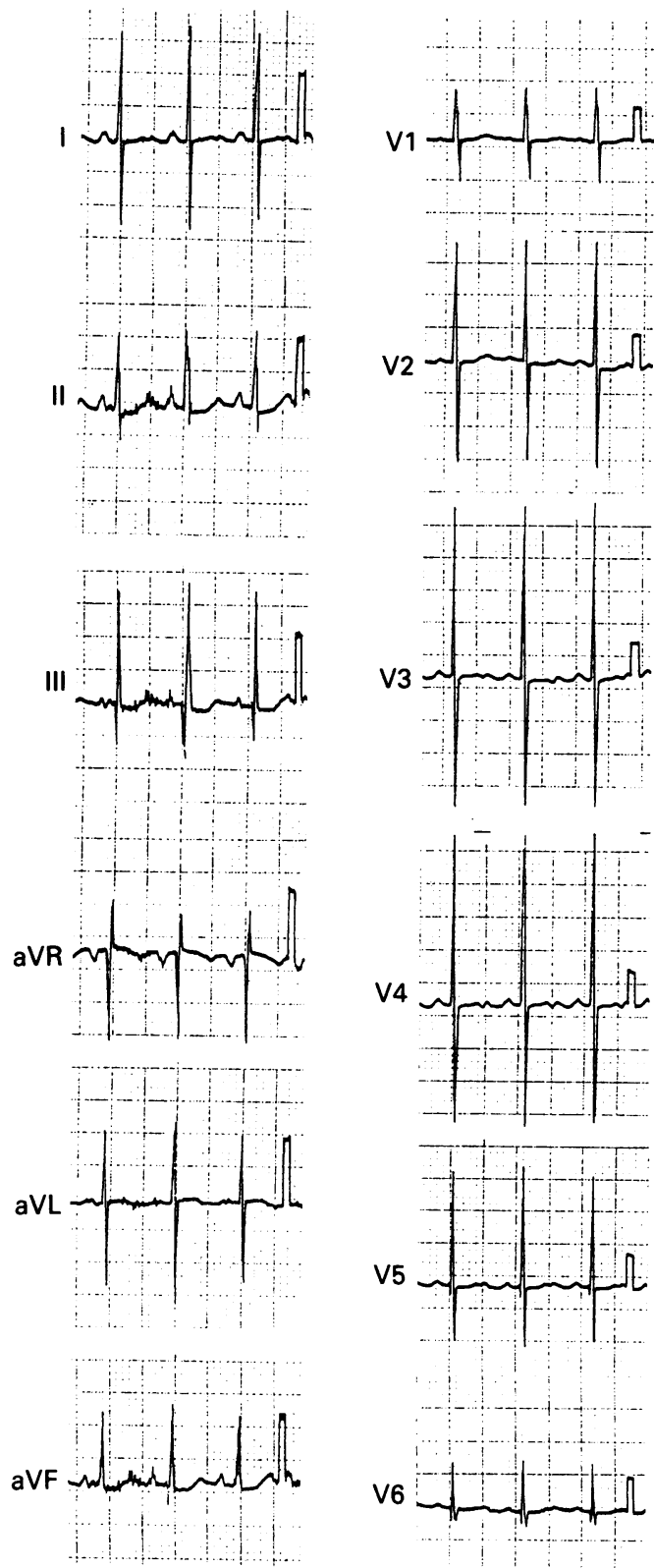

Figure 5 Electrocardiogram in case 3. This 9 month old boy had a complete form of the atypical AVSD. The mean frontal $Q R S$ axis is unusual at $+80^{\circ}$ and the left precordial leads are compatible with biventricular hypertrophy.

\begin{tabular}{|c|c|c|c|c|c|c|c|c|}
\hline Patient No & 3 & 2 & 9 & 1 & 4 & 5 & 6 & 7 \\
\hline $\begin{array}{l}\text { Mean } \\
\text { QRS axis }\end{array}$ & +80 & +110 & +80 & +30 & +160 & +120 & +10 & +45 \\
\hline $\begin{array}{l}\text { Frontal } \\
\text { loop }\end{array}$ & & & & & & & & \\
\hline $\begin{array}{l}\text { Sagittal } \\
\text { loop }\end{array}$ & & & & & & & & \\
\hline $\begin{array}{c}\text { Horizontal } \\
\text { loop }\end{array}$ & 2 & & & & & & & \\
\hline
\end{tabular}

Figure 7 Vector analyses of the QRS complex in patients with atypical atrioventricular septal defect.

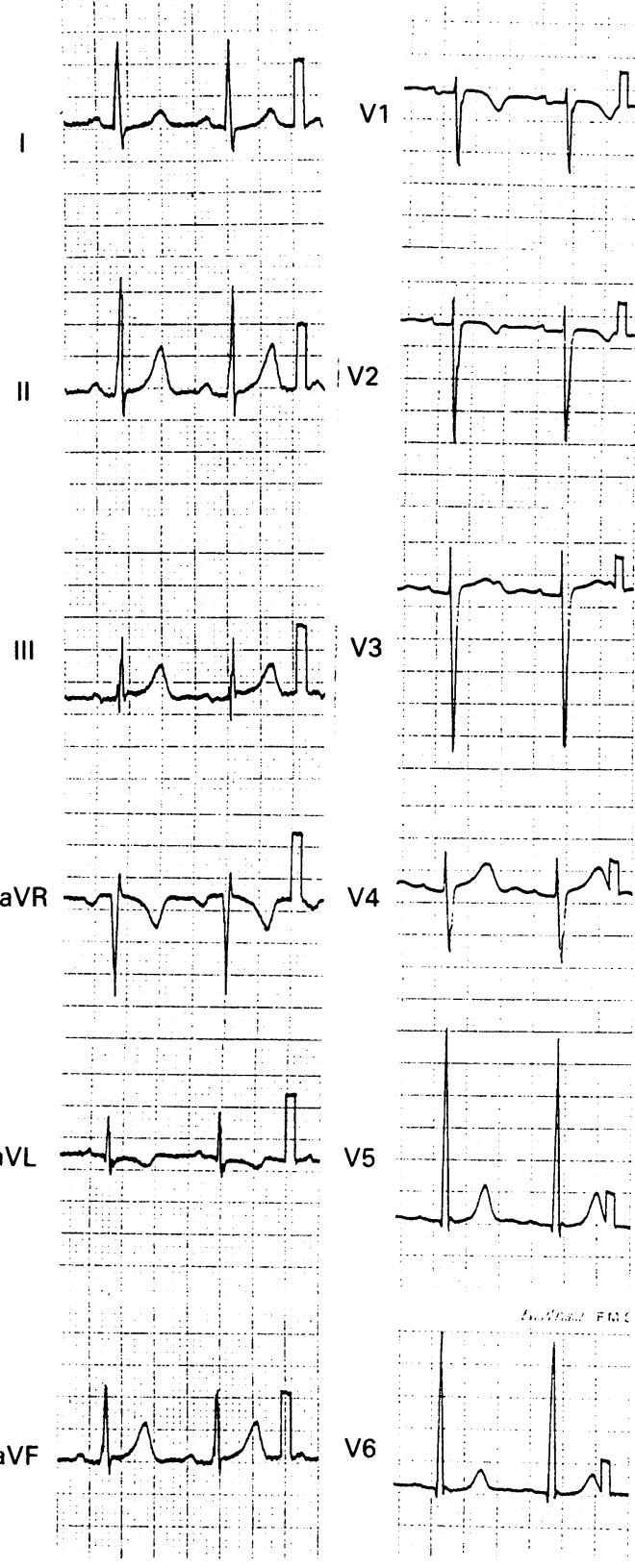

Figure 6 Electrocardiogram in case 7. This 7 year old girl had an incomplete form of the atypical AVSD. The mean frontal $Q R S$ axis is unusual at $+45^{\circ}$ and there are no signs of right ventricular volume overload.

complete type. In the vectorial analyses the initial frontal QRS vector force is usually superior to the left and moves counterclockwise. The left sagittal loop usually shows a clockwise rotation. ${ }^{3-6}$ These abnormal electrocardiographic patterns are considered to be the result of posteroinferior displacement of the atrioventricular conduction system, caused by the anatomical features of AVSD. ${ }^{3-5}$

There are some reported cases of AVSD with an intermediate axis or a right axis deviation. $^{6-8}$ To our knowledge, however, no one has described the atypical morphology we report here or its relations to the electrocardiographic findings. In our study all patients with atypical AVSD showed the unusual mean frontal QRS axis as well as an unusual movement of the QRS loop, in both the 
complete and the incomplete forms. None of the patients with associated cardiac anomalies had atypical AVSD or the unusual QRS axis.

Thiene et al described the relation between the location of the atrioventricular node and the degree of development of the atrial septum, reporting that the more deficient the atrial septum the more posteriorly deviated the node. ${ }^{5}$ Tenckhoff et al reported that the absence of left axis deviation was associated with a left ventricular inflow tract of normal length. ${ }^{7} \mathrm{We}$ evaluated the degree of deficiency of the ventricular inlet septum, which was measured by echocardiography by Gutgesell et al. ${ }^{9}$ In atypical AVSD deficiency of the ventricular inlet septum was milder than that in typical AVSD. From these findings we conclude that atypical AVSD is related to the degree of posteroinferior displacement of the atrioventricular conduction system.

Atypical AVSD was also associated with Down's syndrome. Matsuo et al and Marino et al reported that patients with Down's syndrome and AVSD had various types of minor cardiac anomalies but not this atypical morphology..$^{11}$ Careful inspection is indispensable to evaluate this type of anomaly, particularly in Down's syndrome.

Van Mierop et al described several types of AVSD, including AVSD with intact atrial septum, ${ }^{12}$ and Seo et al reported a case with this type of defect. ${ }^{13}$ Silverman et al and Anderson et al also reported an unusual type of AVSD with intact atrial and ventricular septal structures. ${ }^{214}$ The atypical AVSD in our study is certainly one of the variant forms in the morphological range of this disorder.

None of the patients with atypical AVSD had complete heart block after cardiac repair. We suggest that the ordinary surgical procedures for AVSD are effective for this atypical morphology because the risk of damage to the atrioventricular node and the penetrating bundle remains low.

In conclusion, we encountered nine patients with an atypical form of atrioventricular septal defect characterised by a well formed atrial septum, a milder downward displacement of the atrioventricular valves, and a shorter length of the ostium primum defect. This atypical morphology was one of the causes of the unusual QRS axis, which may be related to the degree of posteroinferior displacement of the conduction system. Most of the patients had Down's syndrome. Further examination of the anatomy and electrophysiology of the conduction system should clarify the cause of the unusual QRS axis in this disorder.

We thank Professor Hiromi Kurosawa and Dr Fred Shane for their help in preparing the manuscript. This study was supported in part by a research grant in 1991 from the Vehicle Racing Commemorative Foundation, Tokyo.

1 Anderson RH. New light on the morphogenesis of atrioventricular septal defects. Int f Cardiol 1988;18:79-83.

2 Anderson RH, Baker EJ, Ho SY, Rigby ML, Ebels T. Th morphology and diagnosis of atrioventricular septa defects. Cardiol Young 1991;1:290-305.

3 Feldt RH, DuShane JW, Titus JL. The atrioventricula conduction system in persistent common atrioventricular canal defect. Circulation 1970;42:437-44.

4 Boineau JP, Moore EN, Patterson DF. Relationship between the ECG, ventricular activation, and the ventricular conduction system in ostium primum ASD. Circulation 1973;48:556-64.

5 Thiene G, Wenink ACG, Frescura C, Wilkinson JL Gallucci V, Ho SY, et al. Surgical anatomy and pathology of the conduction tissues in atrioventricular defects. $\mathcal{f}$ Thorac Cardiovasc Surg 1981;82:928-37.

6 Ongley PA, Pongpanich B, Spangler JG, Feldt RH. The electrocardiogram in atrioventricular canal. In: Feldt RH, ed. Atrioventricular canal defects. Philadelphia: W B RH, ed. Atrioventricular

7 Tenckhoff L, Stamm SJ. An analysis of 35 cases of the complete form of persistent common atrioventricular canal. Circulation 1973;48:416-27.

8 Fournier A, Young ML, Garcia OL, Tamer DF, Wolf GS. Electrophysiologic cardiac function before and afte surgery in children with atrioventricular canal. $\mathrm{Am}$ Cardiol 1986;57:1137-41.

9 Gutgesell HP, Huhta JC. Cardiac septation in atrioventricular canal defect. $₹ \mathrm{Am}$ Coll Cardiol 1986;8:1421-4.

10 Matsuo N, Oshima M, Naganuma M, Shimizu K, Okada R, Sperling DR. Major and minor anomalies in Japanese children with Down's syndrome. $f_{p n}$ Heart $\mathcal{f}$ 1972;13:307-16.

11 Marino $B$, Vairo U, Corno A, Nava S, Guccione $P$, Calabro $\mathbf{R}$, et al. Átrioventricular canal in Down synCalabro R, et al. Atrioventricular canal in Down syn-

12 Van Mierop LHS, Alley RD, Kausel HW, Stranhahen A. The anatomy and embryology of endocardial cushion defect. $\mathcal{F}$ Thorac Cardiovasc Surg 1962;43:71-83.

13 Seo K, Ishihara S, Hara S, Kurosawa H, Takanashi Y. A case of ECD without interatrial communication [English abstract]: Nippon Kyobu Geka Gakkai Zassh 1986;34:2017-20.

14 Silverman NH, Ho SY, Anderson RH, Smith A Wilkinson JL. Atrioventricular septal defect with intact atrial and ventricular septal structures. Int $\mathcal{f}$ Cardio 1984;5:567-72. 